\title{
Diagnosis of aortic stenosis from the carotid pulse and its derivative
}

\author{
Isaac Starr, Christophe Ambrosi, Joel H. Manchester, and James C. Shelburne \\ From the Departments of Therapeutic Research, and Medicine, Cardiovascular-Pulmonary Division \\ School of Medicine, University of Pennsylvania, Philadelphia, Pennsylvania, U.S.A.
}

Using apparatus capable of transmitting its high frequency components, the carotid pulse and its first time derivative have been recorded on 348 cardiac patients, the aortic valve gradient having been measured in more than half.

Bisferiens, plateau, and anacrotic pulses, long associated with aortic stenosis in the older published reports were not significantly associated with that lesion in our data. $P D_{\max }$, the maximum slope of the pulse wave front, was significantly associated with aortic stenosis; normal values effectively excluded that diagnosis, but subnormal values identified only about one-half our cases.

When $P D_{\max }$ was combined with evidence of disturbed blood flow in the carotid artery a non-invasive method was secured, which was very effective in both diagnosing and excluding aortic stenosis.

Since James Hope published his observations in 1835, many reports have described an association between aortic stenosis and certain abnormalities of the peripheral arterial pulse. Thus, textbooks (Conn and Horwitz, 1971 ; Friedberg, 1949; Pullen, 1950) state that a slow rise to the peak of the wave, an anacrotic notch, a flat-topped (plateau) pulse, and a pulse with a doubled peak (bisferiens) are associated with this lesion. Illustrations of all these abnormalities are given by Wood (1958). It is equally true, however, that most authors have found a normal peripheral pulse far more often than an abnormal one in aortic stenosis; Wood (1958), attributes the discrepancy to differences in the degree of stenosis and to the secondary effects of complicating aortic insufficiency.

Such conclusions can be criticized from two viewpoints. Most of the older studies, like that of Wood (1958), were made on series of cases diagnosed as aortic stenosis. But one looks in vain for information about the frequency of similar pulse abnormalities in cardiac cases without aortic stenosis. Without that information the diagnostic value of such abnormalities cannot be properly assessed.

The second criticism is concerned with the methods used to record the pulse both in the older and in some more recent studies (Robinson, 1963). High

Received 13 March 1973.

${ }^{1}$ Studies supported by grants from USPHS, National Institutes of Health. frequency information is lost as the pulse wave travels down the arteries, and apparatus containing air transmission systems, rubber membranes, and rubber tubing also distorts the signal. Smith (1955), taking carotid pulse records on a case of aortic stenosis with an air transmission system like that used in many of the older studies, recorded the 'bisferiens' pulse so often described as characteristic of that lesion; but when he improved his apparatus by greatly reducing the size of the airchamber, the pulse record changed its character completely and a high frequency distortion manifested itself. One wonders whether such artefacts have not entered into many of the older results.

For the past 1o years, in conjunction with ballistocardiographic studies (Starr and Noordergraaf, 1967), carotid pulses and pulse derivatives have been taken by electrical apparatus capable of transmitting high frequency information. These records have been taken in a total of 348 cardiac patients, cardiac catheterization having also been performed in 179 of them. The series included 64 cases of manifest aortic valve disease; the remaining 284 cardiac patients were without clinical evidence of aortic valve lesions. So we have been able to assess the value of the older methods of diagnosing aortic stenosis from pulse abnormalities by statistical calculations and, after finding that they were very ineffective, to devise new methods which proved much better for this purpose. 


\section{Apparatus}

We used a Brecht and Boucke (1953) pulse transducer advertised to give a true response up to 200 cycles per second. A standard differentiating circuit, and two channels for a Sanborn Twin-viso were also used.

\section{Subjects and methods}

All were ambulatory cardiac in-patients at the University Hospital, and they lay supine in the hammock of our ballistocardiograph for at least 15 minutes before records of the carotid pulse and its derivative were taken; our method of applying the sensor to the carotid artery (Starr et al., 1973) and of calibrating the pulse derivative have been described (Starr and Ogawa, 1963).

Catheterization was performed a few days before or after the pulse was recorded. Aortic valve gradients were secured by pull-backs across the aortic orifice. Gradients exceeding $20 \mathrm{mmHg}$ were considered abnormal.

Normal values for $\mathrm{PD}_{\max }$, the maximum rate of pressure rise in the pulse wave front, or the height of the pulse derivative, are given by Starr and Ogawa (1963) and by Masen et al. (1964) for the brachial pulse. 440 $\mathrm{mmHg} / \mathrm{sec}$, twice the standard deviation below the mean, has been taken as the lower normal limit of $\mathrm{PD}_{\max }$ in this study.
The diagnoses used are those made by the hospital staff without knowledge of our findings in the pulse.

\section{Results and discussion}

The relations of five pulse abnormalities to the normality and abnormality of the aortic valve gradient are given in Table I; their relation to the clinical diagnosis of aortic stenosis is shown in Table 2. Obviously the two sets of results are very similar.

The form abnormalities of the conventional pulse, anacrotic, plateau, or bisferiens pulses occurred infrequently in our cases. Since Smith's (1955) results show clearly that such contour abnormalities may be caused by artefacts due to faulty design of the older apparatus our failure to find them more frequently may be due to the superior design of our apparatus. But we did encounter such contour abnormalities occasionally, both in cases of aortic stenosis, and in cardiac patients without that lesion.

Tables $I$ and 2 show clearly that the presence or absence of these contour abnormalities has no significant relation to gradient abnormality nor to the diagnosis of aortic valve disease in our cases. As

TABLE I Relations between certain abnormalities of carotid pulse, and combinations thereof, and normality and abnormality of pressure gradients across aortic valve

\begin{tabular}{|c|c|c|c|c|}
\hline \multirow[t]{2}{*}{ Findings in carotid pulse } & \multicolumn{2}{|c|}{$\begin{array}{l}\text { No. of cases in which } \\
\text { pressure gradient is: }\end{array}$} & \multirow[t]{2}{*}{$\chi^{2}$} & \multirow[t]{2}{*}{ Significance } \\
\hline & Abnormal & Normal & & \\
\hline High frequency abnormality present & 23 & I9 & & \\
\hline High frequency abnormality absent & 5 & 132 & 64 & $<0.01$ \\
\hline $\mathrm{PD}_{\max }<440 \mathrm{mmHg} / \mathrm{sec}$ & 24 & 33 & & \\
\hline $\mathrm{PD}_{\max }>440 \mathrm{mmHg} / \mathrm{sec}$ & 4 & II8 & 44 & $<0.01$ \\
\hline High frequency abnormality present and $\mathrm{PD}_{\max }$ subnormal & 21 & 6 & & \\
\hline $\begin{array}{l}\text { One or both absent } \\
\text { High frequency abnormality present, or } \mathrm{PD}_{\max } \text { subnormal }\end{array}$ & $\begin{array}{r}7 \\
26\end{array}$ & $\begin{array}{r}145 \\
46\end{array}$ & 93 & $<0.01$ \\
\hline Both absent (pulse normal) & 2 & IO5 & 38 & $<0.01$ \\
\hline Anacrotic, plateau, or bisferiens pulse present & 7 & 36 & & \\
\hline Normal contour & 24 & 120 & 0.003 & NS \\
\hline
\end{tabular}

TABLE 2 Relation between abnormalities of carotid pulse and clinical diagnosis of aortic valve disease in cardiac cases

\begin{tabular}{|c|c|c|c|c|c|c|c|}
\hline \multirow[t]{2}{*}{ Clinical diagnosis } & \multirow{2}{*}{$\begin{array}{l}\text { No. of } \\
\text { cases }\end{array}$} & \multicolumn{6}{|c|}{ Carotid pulse abnormalities present } \\
\hline & & $\begin{array}{l}\text { High } \\
\text { frequency } \\
\text { abnormality }\end{array}$ & $\begin{array}{l}P D_{\max } \\
\text { subnormal }\end{array}$ & $\begin{array}{l}\text { Anacrotic } \\
\text { notch }\end{array}$ & $\begin{array}{l}\text { Plateau } \\
\text { pulse }\end{array}$ & $\begin{array}{l}\text { Bisferiens } \\
\text { pulse }\end{array}$ & $\begin{array}{l}\text { Total } \\
\text { last } 3\end{array}$ \\
\hline $\begin{array}{l}\text { Aortic stenosis with or without regurgitation } \\
\text { Aortic regurgitation without stenosis } \\
\text { Cardiac disease without aortic valve } \\
\text { abnormality }\end{array}$ & $\begin{array}{l}35 \\
29 \\
284\end{array}$ & $\begin{array}{l}89 \% \\
48 \% \\
<\text { I } \%\end{array}$ & $\begin{array}{l}69 \% \\
17 \%\end{array}$ & $\begin{array}{l}3 \% \\
0\end{array}$ & $\begin{array}{l}14 \% \\
17 \%\end{array}$ & $\begin{array}{l}3 \% \\
0\end{array}$ & $\begin{array}{l}20 \% \\
17 \% \\
22 \%\end{array}$ \\
\hline
\end{tabular}


evidence for the presence or absence of aortic stenosis in any case, such findings are worthless.

Experience with models throws light on the physiological genesis of such pulse abnormalities, and permits a satisfactory interpretation of our findings. When systole is simulated in cadavers (Starr and Noordergraaf, 1967), or in electrical models of the heart and circulation (Verdouw, 1970; Starr, Verdouw, and Noordergraaf, 1973b), anacrotic, plateau, and bisferiens pulses are easily produced by simulating ejection velocity curves with flat or doubled peaks; that is, they are produced by a physiological mechanism unrelated to aortic stenosis. Obviously one has the right to believe that similar abnormalities of ejection velocity were the genesis of the pulse abnormalities we encountered in the clinic. So, while one can no longer think of aortic stenosis as being the immediate and direct cause of such pulse abnormalities, it might be a remote cause, for the myocardial handicap imposed by such a lesion might lead to a degeneration of myocardial function that would make the ejection velocity curve abnormal, and so produce the pulse contour abnormalities we found in a few patients. The same mechanism would account for the presence of similar pulse abnormalities when other cardiac lesions are present.

A slow rise of pressure on the pulse wave front is by far the best of the older methods of diagnosing aortic stenosis from the pulse. $\mathrm{PD}_{\max }$, the amplitude of the pulse derivative, and the maximum slope of the conventional pulse wave front, is a good way of measuring this. In a previous study (Starr and Ogawa, 1962), average slopes of pulse wave fronts were so closely correlated with $\mathbf{P D}_{\max }$ that there is no need to make both measurements. In our data (Tables $I$ and 2), $\mathrm{PD}_{\max }$ is related both to an abnormal gradient and to the clinical diagnosis of aortic stenosis; $\chi^{2}$ is very high and this relation is highly significant.

But our data also indicate that, if $\mathbf{P D}_{\max }$ is found to be subnormal in any case, the prediction that the gradient is abnormal would be correct less than half the time. If $P D_{\max }$ is found to be normal the prediction that the gradient is normal would be correct in 97 per cent, an impressive value.

A subnormal $\mathrm{PD}_{\max }$ and a slow rise of the pulse to its peak are readily produced in models (Starr and Noordergraaf, 1967; Verdouw, 1970; Starr et $a l$., I973b) by simulating weak systoles with an ejection curve of low initial acceleration. In the clinic, low $\mathrm{PD}_{\max }$ is found in moribund patients, so this abnormality has no necessary relation to any cardiac lesion. When found in aortic stenosis a low $\mathrm{PD}_{\max }$ indicates that the myocardium has not compensated for the increased impedance by contracting more strongly. This occurred so frequently in our cases that this finding aids in the detection of aortic stenosis.

The high frequency abnormality found in the carotid artery in these studies has been described in detail elsewhere (Starr et al., 1973a). The burst of high frequency distortion appearing at and after the main peak of the pulse derivative is to be attributed to disturbed blood flow in the artery. An example of such a record is given in Fig. I, where a record of the same patient after operative correction of his aortic stenosis is also shown.

Tables $I$ and 2 demonstrate that this finding is strongly related both to abnormality of the gradient and to the diagnosis of aortic stenosis; indeed, $\chi^{2}$ is very high (Table I). Nevertheless, judged by our findings, if the high frequency abnormality was present in any case, the prediction that the gradient exceeded $20 \mathrm{mmHg}$ would be correct in only 55 per cent of cases, largely because of the numerous cases of aortic regurgitation which show the high frequency abnormality, despite a normal gradient. On the other hand, a prediction that the gradient was normal, made from the absence of the high fre-
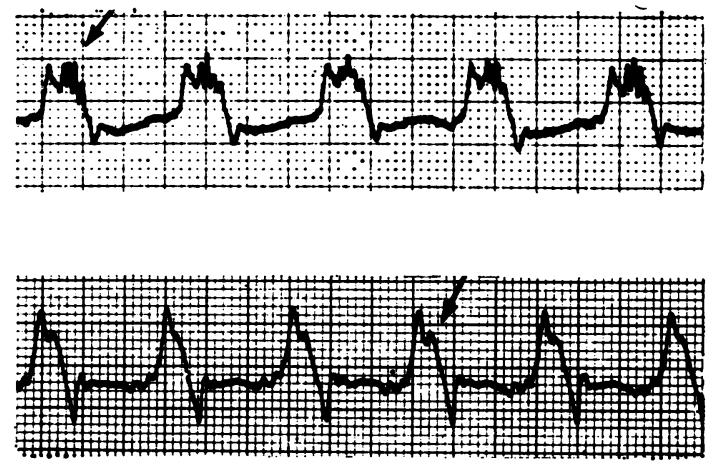

FIG. I The high frequency abnormality, as seen in the carotid pulse derivative of typical cases of aortic stenosis. Patient aged 68. Aortic stenosis with some regurgitation, probably syphilitic. Above: record secured before operation; the aortic valve gradient was $47 \mathrm{mmHg}$; $P D_{\max } 42 \mathrm{mmHg} / \mathrm{sec}$, a value below lower normal limits; blood pressure $160 / 70 \mathrm{mmHg}$. Below: record taken three weeks after the insertion of a caged ball prosthesis into the aortic orifice. $P D_{\max }=817$ $\mathrm{mmHg} / \mathrm{sec}$, blood pressure $150 / 95 \mathrm{mmHg}$.

Note the high frequency abnormality (marked), the burst of high frequency distortion found at the peak of the main wave of every systolic complex of the preoperative record. Note also the complete disappearance of the high frequency abnormality after the insertion of the artificial valve; a single small notch remains (marked). 


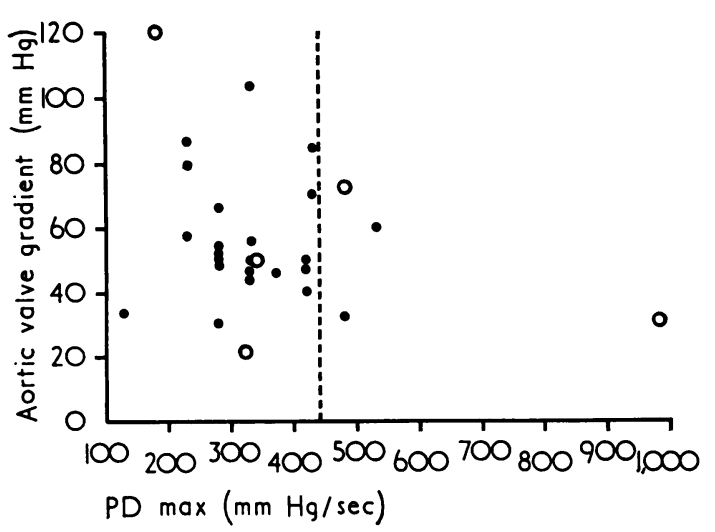

FIG. 2 Relation of the magnitude of $P D_{\max }$ to that of the aortic valve gradient in 28 cases of aortic stenosis diagnosed by an abnormally raised gradient. The broken line indicates the lower normal limit of $P D_{\max }$ i.e. $2 S D$ below the mean value for healthy persons. Cases having the carotid high frequency $a b-$ normality are represented by small dots, those without this abnormality by open circles.

Note that when the gradient is abnormal, $P D_{\max }$ is subnormal in the great majority of cases.

quency abnormality, would be correct in 96 per cent, an impressive value.

By taking both the high frequency abnormality and $\mathbf{P D}_{\max }$ into account, our ability to diagnose aortic stenosis is much increased. Thus, if the high frequency abnormality is present and $\mathbf{P D}_{\max }$ is subnormal, the prediction of an abnormal gradient would be correct in 78 per cent (Table $\mathrm{I}$ ). If one arbitrarily changes the lower normal limit of $\mathrm{PD}_{\max }$ from 440 to $550 \mathrm{mmHg} / \mathrm{sec}$, all but one $(98 \%)$ of our cases of abnormal gradient could be identified by this combination (Fig. 2). If the high frequency abnormality is absent and $\mathbf{P D}_{\max }$ is normal, an opinion that the gradient was normal would be correct in 98 per cent of our cases. This is most unusual diagnostic accuracy. Presumably, the increased effectiveness of the combination is due to two facts: a very low $\mathrm{PD}_{\max }$ identifies those cases in which ejection velocity is too low to produce disturbed flow, and a very high value detects the group in which ejection velocity is so high that disturbed aortic flow may be present when there is roughening, without narrowing, of the aortic orifice.

The $\chi^{2}$ values given in Table I show clearly that such new non-invasive methods are far superior to the old for the diagnosis of aortic stenosis.

\section{References}

Brecht, K., and Boucke, H. (1953). Zur Abnahme des Arterienpulses am Menschen mit den Infraton-Mikrophon. Pflügers Archiv für die gesamte Physiologie des Menschen und der Tiere, 257, 490.

Conn, H. L., Jr., and Horwitz, O. (1971). (Editors.) Cardiac and Vascular Diseases. Lea and Febiger, Philadelphia.

Friedberg, C. K. (1949). Diseases of the Heart. Saunders, Philadelphia and London.

Hope, J. (1835). A Treatise on the Diseases of the Heart and Great Vessels, 2nd ed. Kidd, London.

Mason, D. T., Braunwald, E., Ross, J., Jr., and Morrow, A. G. (1964). Diagnostic value of the first and second derivatives of the arterial pressure pulse in aortic valve disease and hypertrophic subaortic stenosis. Circulation, 30, 90.

Pullen, R. L. (1950). Medical Diagnosis; Applied Physical Diagnosis, 2nd ed. Saunders, Philadelphia.

Robinson, B. (1963). The carotid pulse. I. Diagnosis of aortic stenosis by external recordings. British Heart fournal, $25,51$.

Smith, J. E. (1955). A technique for recording carotid artery pulsations with special reference to aortic stenosis. American Heart fournal, 4, 428.

Starr, I., Ambrosi, C., Manchester, J. H., and Shelburne, J. C. (1973a). Disturbed blood flow in aortic valve disease. American Heart fournal. In the press.

Starr, I., and Noordergraaf, A. (1967). Ballistocardiography in Cardiovascular Research; Physical Aspects of the Circulation in Health and Disease. Lippincott, Philadelphia.

Starr, I., and Ogawa, S. (1962). Quantitative studies on the 'quickness' of the pulse. American fournal of the Medical Sciences, 243, 309.

Starr, I., and Ogawa, S. (1963). A clinical study of the first derivative of the brachial pulse. Normal standards and abnormalities encountered in heart disease. American Heart fournal, 65, 482.

Starr, I., Verdouw, P. D., and Noordergraaf, A. (1973b). Clinical evidence of cardiac weakness and incoordination, secured by simultaneous records of the force $\mathrm{Bcg}$ and carotid pulse derivative and interpreted by an electrical analogue. American Heart fournal, 85, 341.

Verdouw, P. D. (1970). Ballistics of Ventricular Performance. A Dissertation in Biomedical Engineering. University of Pennsylvania.

Wood, P. (1958). Aortic stenosis. American fournal of Cardiology, $\mathbf{1}, 553$.

Requests for reprints to Dr. Isaac Starr, 85I Gates Memorial Pavilion, University Hospital, 36th and Spruce Streets, Philadelphia, Pennsylvania, I9I04, U.S.A. 